\title{
Group Risk Parity Strategies for ETFs Portfolios
}

\author{
Massimiliano Kaucic, Giorgio Valentinuz \\ University of Trieste, Trieste, Italy
}

\begin{abstract}
This research aims to compare different strategies that a non-professional investor in exchange-traded funds (ETFs) could employ to reach a good performance both from profits and from a risk perspective. In recent years, especially after the 2008 crisis, a new technique to evaluate the risk has become more popular, the so-called risk parity, which seeks to equalise the contributions to risk of the portfolio constituents. Our study analyses 17 variants of risk parity portfolio design for groups with the minimum variance strategy and equally weighted portfolio over a pool of 56 ETFs-listed on the Italian Stock Exchange—of eight different categories of specialisation. Empirical results confirm the usefulness of the group risk parity strategies in improving outcomes regarding diversification of risks among classes with good out-of-sample performance with respects to the target models.
\end{abstract}

Keywords: group risk parity, portfolio selection, exchange-traded funds, group constraints, bound constraints, passive investing, Italian Stock Exchange

\section{Introduction}

In the last 10 years, investing in profitable products - trying, in the meantime, to maintain the investment risk at an acceptable level—has been an arduous task because of low-interest rates and high shares prices volatility in most of the worldwide stock exchanges. In this environment, the risk-free asset became a false investment opportunity (in particular in Europe) for whom was searching to get a positive real rate of return; the most powerful tool to reduce risk-as a core principle of investing suggests - is portfolio diversification. Retail investors have different types of investment to choose from to spread out risk, but for some of them, the minimum amount of capital to build a diversified portfolio is relevant and the liquidity is limited.

Exchange-traded funds (ETFs) are baskets of securities that commonly track the performance of a benchmark index and are traded on exchange markets, like individual stocks. Choosing among many assets classes, with a limited outlay of capital, thanks to low investment thresholds, and with higher liquidity than mutual funds, they permit everybody to diversify their investment at low costs. In any case, after the 2008 financial crisis, the holding of ETFs has increased enormously in portfolios managed by institutional investors (hedge funds, pension funds, insurers, private banks, and wealth managers); and new and innovative ETFs with different underlying assets and different characteristics (e.g., environmental, social, and governance ETFs) have been launched on the markets, enlarging investment opportunities for retail investors, too. Nowadays, anyone

\footnotetext{
Massimiliano Kaucic, Ph.D., adjunct professor, Department of Economics, Business, Mathematical and Statistical Sciences-DEAMS, University of Trieste, Trieste, Italy.

Giorgio Valentinuz, Ph.D., adjunct professor, Department of Economics, Business, Mathematical and Statistical Sciences-DEAMS, University of Trieste, Trieste, Italy.

Correspondence concerning this article should be addressed to Giorgio Valentinuz, Department of Economics, Business, Mathematical and Statistical Sciences-DEAMS, University of Trieste, Via dell'Università 1, Trieste 34123, Italy.
} 
with a brokerage account can invest together with the professionals at lowering fees.

Several studies in the literature examine whether these investments provide a cost-effective benefit for the investors. Tsai and Swanson (2009) showed that ETFs provide greater diversification benefits. Huang and Lin (2011) proved the reasonability of the international diversification strategy. Also, they pointed out that the same expected returns and the same diversification levels can be attained through ETFs instead of investing in the target market indices. The study by Buetow and Henderson (2012) confirmed these findings. Roll (2013) suggested that ETFs representing different asset classes may be the best proxies for the unobservable market risk drivers, thus representing the best diversification potential for investors. Accordingly, Puelz, Carvalho, and Hahn (2015) proposed a portfolio selection procedure that uses a Bayesian regression model to identify a reduced number of ETFs representing the major dimensions of risk in the market.

The paper contributes to this body of research by analyzing various risk-based portfolio optimization strategies with the goal to propose some investment approaches for the householder who uses ETFs as the unique financial instrument to build diversified portfolios (different geographical areas, different asset classes, and different styles) and has no quantitative model to forecast the future market conditions. For this type of investors, constructing portfolios in such a way to receive the maximum profits with the minimum possible risk could result inappropriate and better results can be obtained through models that specifically concentrate on the risk structure of the investment (Roncalli, 2013). Moreover, risk-based strategies have provided a systematic way to outperform capitalisation-weighted benchmarks with the maximum level of diversification in the past, uncertain market (Qian, 2005; Khuzwayo, 2011; Braga, 2015). Due to its popularity among practitioners and the effectiveness in portfolio allocation with multi-asset classes (Bai, Scheinberg, \& Tutuncu, 2016) and with equities (Lohre, Neugebauer, \& Zimmer, 2012; Siu, 2014), we assess the usefulness of the risk parity paradigm in ETFs investing. The idea is to equalise the sources of risk of a portfolio to control and possibly reduce losses. In particular, we focus on risk parity strategies over groupings of ETFs with the objective to find the more effective in term of the risk contribution from groups instead of individual assets. The requirement of risk parity at the group level dictates the choice of assets from a top-down perspective. In this manner, investors can implicitly limit the number of positions taken and reduce further transaction costs.

Another aspect we investigate is the role of constraints at the group and individual level in forming optimal portfolios balancing the group risk parity and sparsity objectives. To this end, a set of 56 ETFs listed on the Italian Stock Exchange is analysed. The flexibility of the proposed strategies allows providing better out-of-sample results than the naïve portfolios and minimum variance portfolios.

\section{The Exchange Traded Funds Asset Class}

Since 70s theory suggests to investors to diversify their portfolios (Merton, 1971; Cass \& Stiglitz, 1970) to include all the risky assets available; and-depending on the individual risk aversion-to combine bonds and the market portfolio. However, empirical studies which analysed household portfolios found different investors' behaviors compared to the theoretical suggestions, even if they do not arrive at a single explanation. Some of them find that diversification increases with either investor wealth or income (Kelly, 1995; Polkovnichenko, 2005; Goetzmann \& Kumar, 2008), but other factors affecting investors behaviours could be age, financial sophistication, size of the account balance, portfolio size, labour income, and the ratio of current wealth to income (Calvet, Campbell, \& Sodini, 2007; Ivković, Sialm, \& Weisbenner, 2008; Goetzmann \& Kumar 2008; Kumar, 2009; Roche, Tompaidis, \& Yang, 2013). 
An investment vehicle launched around 25 years ago in the USA-called Exchange Traded Fund (ETF)—is becoming one of the fastest-growing segments of the investment management business (Hill, Nadig, \& Hougan, 2015) completely changing the asset management industry (Itzhak, Franzoni, \& Moussawi, 2017). ETFs are index-based investments grounded on the efficient market theory (Malkiel, 1995; Sharpe, 1965) and quantitative science to portfolio construction (Markowitz, 1952; Bogle, 2015). Depending on their asset classes target, ETFs are usually divided into (1) equity exchange-traded funds exchange-traded funds; (2) fixed income exchange-traded funds; (3) commodity exchange-traded funds; (4) currency exchange-traded funds; (5) alternatives exchange-traded funds; (6) leveraged and inverse exchange-traded funds; and (7) leveraged and inverse exchange-traded funds.

Global ETF assets, which totalled just $\$ 417 \mathrm{~b}$ in 2005 , had reached $\$ 4$.4t by the end of September 2017 -a cumulative average growth rate (CAGR) of around $21 \%$ (EY, 2017). However, passive investments—of which ETFs are the most relevant and innovative-are expected to grow strongly in the next years, becoming a favourite instrument vehicle in index-based strategies of actively managed portfolios (Hill et al., 2015). In any case, the possibility to invest in mutual funds or ETFs not implies that householders prefer to invest in diversified portfolios instead of holding individual stocks (Roche et al., 2013).

The new regulatory environment after the financial crisis (2008 and forwards), especially in the European Union, convinced institutional investors to use ETFs as a substitute for derivatives and individual assets. The new European rules in term of compensation (with the banning of payment of "retrocession" commission) and transparency for financial institutions and insurance companies could favour the use of ETFs thanks to their liquidity, low fees, transparency, and potential higher tax efficiency (Lettau \& Madhavan, 2018; Abner, 2016). Tax efficiency can be obtained, under certain fiscal systems, thanks to the creation and redemption mechanism enabling the transfer of assets without generating tax consequences for all investors (Abner, 2016). At once, the model portfolios using passive investments and the rise of robo-advisors are also longer-term trends that support ETFs use and adoption (Lettau \& Madhavan, 2018).

Like any other investment, ETFs are subject to risks: For plain vanilla unlevered funds, the main risk is the price volatility in the basket of underlying securities. Thanks to the creation/redemption mechanism, the arbitrage works to keep the price of an exchange-traded fund close to the intrinsic value of an ETF's holdings in the underlying market (Lettau \& Madhavan, 2018). Different is the case of synthetic exchange-traded funds, usually affected by counterparty risk because they enter into swap positions with professional investors.

ETFs are an essential way for retail investors to access to many financial market segments, in a liquid, tax efficient, cost-effectiveness, restricted bid/ask spread, and limited capital employment way. Products offered by issuers could be very different: At the beginning, they were typical buy-and-hold (passive) investment instruments, but nowadays, some of them follow an active approach, adapting to changing market conditions, using leverage and derivatives.

ETFs are now the preferred vehicle for factor-based strategies (Hill et al., 2015) that should be able to create an "alpha" (an extra return compared to a benchmark) that could not be obtained by passive investors. Their aptitude to be good funds managers is measured by their ability to minimise the tracking error concerning the index (Itzhak et al., 2017).

Different are the categories of ETFs investors could invest in, with different styles and underlying assets to track. Table 1 -in the absence of a standardised classification-reports the most relevant categories usually 
employed by practitioners. ETNs are not listed in Table 1 because they are issued and backed by major, high credit rating banks as senior debt notes, even if sometimes they are considered as ETFs.

Table 1

A Possible Classification of Different Types of ETFs

\begin{tabular}{ll}
\hline Types of ETFs & What do they track? \\
\hline Market index & Major either national or international market indexes \\
\hline Currency & A specific foreign currency or a basket of currencies \\
\hline Sector/Industry & Usually, a certain index which represents a specific industry \\
\hline Commodity & The commodity price, using derivatives contracts with commodities as underlying assets \\
\hline Style & A certain investment style (e.g., growth vs. value stocks) or market cap style (e.g., large vs. small) \\
\hline Bond & Investments in corporate or government bonds, either at national or international level \\
\hline Real estate & An index that measures the performance of REITs or other specialised vehicles in real estate investments \\
\hline Inverse & With short positions, permit to get an inverse reaction to the movement of the underlying asset \\
\hline Leveraged & They increase the exposure to the price movement of the underlying asset (index, investment product) \\
\hline Actively managed & They not only track an underlying asset with passive behaviour, but they try to beat its performance \\
\hline Dividend & $\begin{array}{l}\text { A dividend index, which includes dividend-paying stocks in the whole market, in some sectors, in some } \\
\text { geographic locations }\end{array}$ \\
\hline Innovative & $\begin{array}{l}\text { Particular indexes, such as the VIX Index (a measure of market expectation of near-term volatility of S \& } \\
\text { P 500 index option prices). Alternatively, ETFs which use particular strategies to obtain their goals }\end{array}$ \\
\hline
\end{tabular}

\section{The Equal Risk Contribution Paradigm in Portfolio Selection}

The seminal work of Markowitz (1952) represents the cornerstone in quantitative portfolio management and the mean-variance analysis is became a key issue in portfolio selection. However, this model has several drawbacks that make difficult its application in practice. A commonly cited pitfall is the sensitivity to the changes in the inputs, in particular, due to the estimation errors associated with the expected values of the assets returns. The forecasts based on historical information, in fact, can be inaccurate predictors of the future behaviour of the assets returns, and optimal portfolios constructed using these predictors can, therefore, be inefficient (Best \& Grauer, 1991). Also, optimal portfolios tend to suffer from concentration in the largest constituents. Hence, from a risk management perspective, the risk associated with small assets may have a great impact on the total risk.

Recently, several allocation strategies have been proposed to reduce these problems by utilising only the information on the assets' volatilities and their correlations (Roncalli, 2013). In this paper, we focus on the so-called risk parity approach, according to which one aims to achieve the diversification in the sense of the portfolio risk instead of the capital allocation. Formally, let us assume we operate in a market with $n$ risky assets and denote by $x=\left(x_{1}, \ldots, x_{n}\right)^{T}$ and $r_{i, t}$ the vector of portfolio weights and the rate of return of asset $i$ at time $t$, with $t=1, \ldots, T$, respectively. Using volatility as the measure of risk, we define the marginal risk contribution of asset $i$ as the ratio $\mathrm{MRC}_{i}=\frac{(C x)_{i}}{x^{T} C x}$, where $C$ is the covariance matrix of the rates of returns of the assets. The quantity $\mathrm{TRC}_{i}=x_{i} \frac{(C x)_{i}}{x^{T} C x}$ defines the total risk contribution of asset $i$ to the portfolio risk.

Assuming that short selling is not allowed, the unique solution to the following system of equations and inequalities 


$$
\left\{\begin{array}{c}
x_{i} \frac{(C x)_{i}}{x^{T} C x}=x_{j} \frac{(C x)_{j}}{x^{T} C x} \forall i, j \\
\sum_{i=1}^{n} x_{i}=1 \\
x_{i} \geq 0 i=1, \ldots, n
\end{array}\right.
$$

is said a risk parity (RP for short) portfolio (Maillad, Roncalli, \& Teïletche, 2010).

In our context, an investor could refer to a basket of hundreds, or even thousands, of ETFs. However, the RP approach, as defined above, implicitly assumes to invest in all the assets, thus resulting unpractical. Useful in this case is the variant called group risk parity (GRP) that diversifies the portfolio risk at the group level (Bai et al., 2016), allowing null weights among the components of the RP portfolio.

Assuming that assets are classified into $l$ groups, $G_{1}, \ldots, G_{l}$, such that (1) each asset belongs to only one group; and (2) we invest in all the groups, the total risk contribution of the $s$-th group is given by the sum of the total risk contributions of its elements, i.e., $\operatorname{TGRC}_{i}=\sum_{i \in G_{s}} x_{i} \frac{(C x)_{i}}{x^{T} C x}$. Then, following the suggestions of Gluzicka (2017), we say that a portfolio allocation is optimal in GRP terms if it is a solution of the optimization problem

$$
\begin{gathered}
\min _{x} \sum_{a=1}^{l} \sum_{b=1}^{l}\left(\sum_{i \in G_{a}} x_{i} \frac{(C x)_{i}}{x^{T} C x}-\sum_{j \in G_{b}} x_{j} \frac{(C x)_{j}}{x^{T} C x}\right)^{2} \\
\sum_{i=1}^{n} x_{i}=1 \\
0 \leq \sum_{k \in G_{s}} x_{k} \leq U_{s} s=1, \ldots, l \\
0 \leq x_{i} \leq u_{i} i=1, \ldots, n
\end{gathered}
$$

where $U_{s}$ and $u_{i}$ are upper bounds on the weight of the $s$-th group and of the $i$-th asset, respectively.

The introduction of group constraints and buy-in thresholds is necessary since minimising violations of risk parity between groups alone is not sufficient for producing interesting investment portfolios (Siu, 2014). Consider, for instance, the solution of the above optimisation problem with one asset randomly selected from each group. This portfolio satisfies the GRP paradigm but is unlikely to have any real-world attractiveness.

\section{Portfolio Strategies Used in the Comparisons}

The first methodology, the naïve equally-weighted portfolio (EW), assumes that risks and returns cannot be predicted (Lee, 2011), thus assigns the same weight to all the assets, i.e., $x_{i}=\frac{1}{n}$, with $i=1, \ldots, n$. EW represents the portfolio with the maximum diversification in terms of capital allocation. Investors acting their decisions according to the EW model are exposed in the same measure to the largest as well as to the smallest assets in the portfolio.

From an out-of-sample perspective, the EW strategy is a suitable test benchmark since it has shown impressive performance with respect to other models on several experiments (DeMiguel, Garlappi, \& Uppal, 2007). 
The second target model is the minimum variance portfolio $(\operatorname{minV})$, which is made up of the least volatile joint collection of assets (Clarke, De Silva, \& Thorley, 2011) and is located on the left-most position of the mean-variance efficient frontier.

In the case of no-short selling, it is the solution to the following optimisation problem:

$$
\begin{gathered}
\min _{x} x^{T} C x \\
\sum_{i=1}^{n} x_{i}=1 \\
x_{i} \geq 0 i=1, \ldots, n
\end{gathered}
$$

This strategy leads to portfolios that are diversified in terms of marginal risk contributions. It leads to concentrated portfolios even if it dominates other strategies from the perspective of low volatility.

\section{Data and Methodology}

In this section, we examine the behaviour of the EW, MinV, and GRP portfolio selection models on an investible universe of 56 ETFs quoted on the Italian Stock Exchange market with an accumulation plan of investment. They have been selected among the ETFs with a Morningstar rating classification at 04/05/2018 (Morningstar, 2018). As reported in the last column of Table 1A in Appendix, these funds can be classified into the following categories:

- Euro Corporate Bonds;

- Eurozone Government Bonds;

- Eurozone Large-Cap Equities;

- Eurozone Large-Cap Blend Equities;

- US Large-Cap Blend Equities;

- Japan Large-Cap Equities;

- Emerging Markets Equities;

- Global Large-Cap Blend Equities.

The pie chart in Figure 1 shows that the Government Bonds form the largest class of funds with 19 constituents (representing 34\% of the data set) while the Eurozone and Japan Large-Cap Equities are the smallest classes with four ETFs each one (corresponding to the $7 \%$ of the data set per group). The remaining classes consist of five to seven elements. It can be noted that grouping the ETFs only in terms of Bond and Equity, the proportions of the two macro-categories are comparable (26 Bonds against 30 Equities).

Thanks to these characteristics, we also analyse how granularity may influence the optimal asset allocation for the GRP strategy, pointing out the relation with the buy-in thresholds and group constraints, which clamp the investment choices. To this end, two variants of risk parity models are compared, the first involving the Bond/Equity classification and the second for the finer grouping with eight classes.

The weekly prices of the funds have been obtained from Bloomberg for the period from January 2013 to May 2018, yielding a total of 277 observations.

We use a rolling time window procedure to rebalance optimal portfolios at regular calendar intervals in order to highlight the different effects of the market changes on the behaviour of the strategies (Eakins \& Stansell, 2007). We solve the optimisation problems for overlapping windows built by moving forward in time with predefined step size. The optimal portfolio found with respect to an in-sample period is held unchanged 
for the following out-of-sample period. Successively, the in-sample window is updated by removing the oldest data and including the most recent information. This procedure is repeated until the last available week. In our analysis, the in-sample and the out-of-sample windows involve 104 and four observations respectively. These parameter choices are typical settings for portfolio selection problems (Hitaj \& Zambruno, 2016).

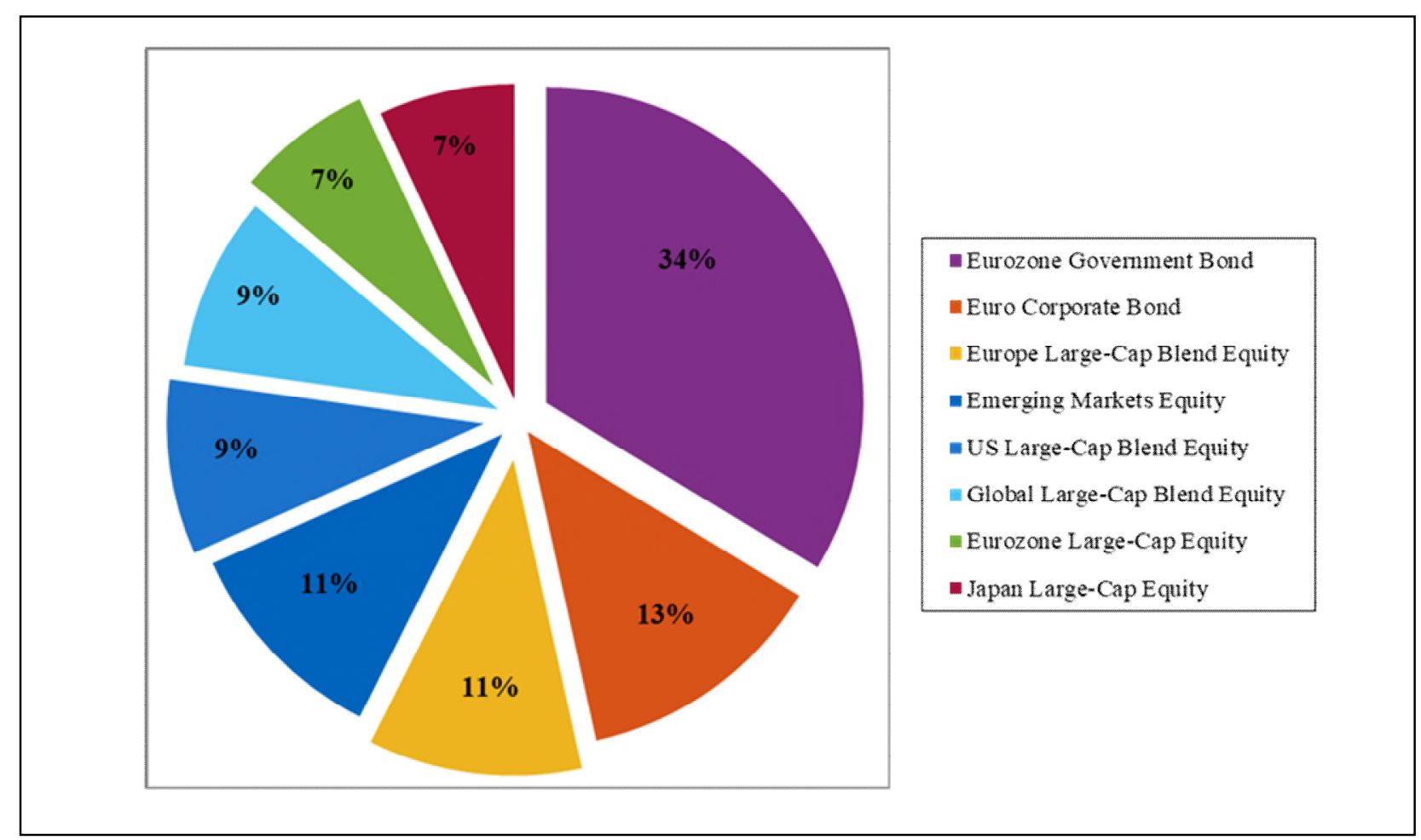

Figure 1. Pie chart of the pool of ETFs used in the empirical study.

\section{Covariance Matrix Estimation}

Since the implementation of the described risk-based strategies solely concerns with the structure of risk in the reference market, we only have to specify the covariance matrix of returns. Due to its effectiveness in reducing the estimation error as well as in lowering the out-of-sample variance of portfolios, we consider the Bayesian shrinkage estimator proposed by Ledoit and Wolf (2003). It is defined as the optimal weighted average of the single-index covariance matrix $F$ by Sharpe (1965) and the sample covariance matrix $C$ as follows

$$
\hat{C}=\alpha F+(1-\alpha) C
$$

where $\alpha$ represents the shrinkage intensity. A closed-form solution for the optimal value of $\alpha$ is provided by Ledoit and Wolf (2004). Following the suggestions of the same authors, we consider the equal-weighted portfolio including all the 56 ETFs as the market index. Note that in our dynamic setting, the covariance matrix estimates $F, C$, as well as the shrinkage intensity $\alpha$ are updated in each in-sample window.

\section{Performance Measures}

The analysis of the models consists of two parts, namely an in-sample and an out-of-sample one. Regarding the former, it focuses on the allocation structure of the risk as well as of the capital for the optimal portfolios. 
Let us denote by $Q$ and $x_{q}=\left(x_{1, q}, \ldots, x_{n, q}\right)^{t}$ the number of rebalances realized and the vector of portfolio weights at the rebalancing time $q$. Then, the total risk contribution of the $i$-th asset at time $q$ is defined as $\operatorname{TRC}_{i, q}=\frac{x_{i, q}\left(\hat{C}_{q} x_{q}\right)_{i}}{x_{q}{ }^{t} \hat{C}_{q} x_{q}}$, with $i=1, \ldots, n$, where $\hat{C}_{q}$ is the estimated covariance matrix for the $q$-th in-sample window. For the in-sample analysis, we consider the following performance measures.

The average on all the rebalancing times of the highest total risk contributions

$$
\operatorname{maxRC}=\frac{1}{Q} \sum_{q=1}^{Q} \max _{i} \mathrm{TRC}_{i, q}
$$

This measure gives an indication of the risk concentration at the individual level.

The average on all the rebalancing times of the normalised version of the Herfindahl index for the distribution of the total risk contributions

$$
\mathrm{NHRC}=\frac{1}{Q} \sum_{q=1}^{Q} \frac{1-\sum_{i=1}^{n}\left(\mathrm{TRC}_{i, q}\right)^{2}}{1-\frac{1}{n}}
$$

In this manner, the term in the outer summation is 0 when all the risk is concentrated in one single asset and is 1 when all the assets have the same percentage of risk contribution. Thus, a portfolio with a higher value for NHRC will be preferred.

The average on all the rebalancing times of the normalised version of the Herfindahl index for the distribution of the weights, which is defined as

$$
\mathrm{NHX}=\frac{1}{Q} \sum_{q=1}^{Q} \frac{1-\sum_{i=1}^{n}\left(x_{i, q}\right)^{2}}{1-\frac{1}{n}}
$$

measures the concentration of weights. Similar to the NHRC indicator, the term in the outer summation is 0 when all the capital is concentrated in one single asset and is 1 for the equal-weighted portfolio. Thus, the highest diversified portfolio presents the highest NHX value.

The average on all the rebalancing times of the highest group risk contributions takes into account the risk concentration at the group level and is calculated as

$$
\operatorname{maxGRC}=\frac{1}{Q} \sum_{q=1}^{Q} \max _{k} \mathrm{TGRC}_{k, q}
$$

where $\mathrm{TGRC}_{k, q}$ represents the total global risk contribution of the $k$-th group of assets, with $k=1, \ldots, G$.

The average on all the rebalancing times of the normalised version of the Herfindahl index for the distribution of the total group risk contributions is defined by

$$
\mathrm{NGHRC}=\frac{1}{Q} \sum_{q=1}^{Q} \frac{1-\sum_{k=1}^{G}\left(\mathrm{GRC}_{k, q}\right)^{2}}{1-\frac{1}{G}}
$$

and measures the risk diversification among the groups. The meaning of this indicator is similar to NHRC.

The group counterpart of the diversification index NHX is given by 


$$
\mathrm{NGHX}=\frac{1}{Q} \sum_{q=1}^{Q} \frac{1-\sum_{k=1}^{G}\left(\sum_{i \in G_{k}} x_{i, q}\right)^{2}}{1-\frac{1}{G}}
$$

where $G_{k}$ is the $k$-th group of assets. The meaning of this statistics is similar to NHX; now, the concentration measure is provided at the group level.

Another information we consider in the comparisons is the number of assets with positive weight. In order to take into account the evolution of rebalances, the average value is used

$$
\text { AnStocks }=\frac{1}{Q} \sum_{q=1}^{Q} \sum_{i=1}^{n} \mathbb{I}\left(x_{i, q} \neq 0\right)
$$

where $\mathbb{I}(\cdot)$ represents the indicator function, combined to the standard deviation (STDnStocks). Sparser portfolios are preferable.

Let us denote by $t_{0}$ and $T$ the last in-sample and the last out-of-sample time respectively and let us indicate the portfolio rates of return for each model in the out-of-sample period with $r_{t}^{\text {out }}, t=t_{0}+1, \ldots, T$. The following performance measures are used in the out-of-sample analysis.

The Sharpe ratio (Sharpe, 1965), which evaluates the compensation earned per unit of portfolio total risk. It is defined as the ratio between the annualised average $\mu^{\text {out }}$ of $r_{t}^{\text {out }}$, and the annualized sample standard deviation $\sigma^{\text {out }}$ as follows

$$
S R=\frac{\mu^{\text {out }}}{\sigma^{\text {out }}}
$$

Higher values of SR are preferable.

The downside risk is measured by the maximum drawdown, which represents the maximum loss from a peak to a trough before a new peak is attained. More precisely, let us consider the cumulative out-of-sample portfolio returns, which correspond to the values of wealth after $t$ periods

$$
W_{t}=W_{t-1}\left(1+r_{t}^{o u t}\right)
$$

with $t=t_{0}+1, \ldots, T$ and $W_{t_{0}-1}=1$, then the drawdowns are defined as

$$
D D_{t}=-\frac{W_{t}-\max _{t_{0}+1 \leq s \leq t} W_{s}}{\max _{t_{0}+1 \leq s \leq t} W_{s}}
$$

The maximum drawdown, which corresponds to the largest loss achieved over the out-of-sample, is

$$
M D D=\max _{t_{0}+1 \leq s \leq t} D D_{s}
$$

Finally, to get an impression of the transaction costs involved, we calculate the average turnover over the out-of-sample period as defined in DeMiguel et al. (2007)

$$
\text { TO }=\frac{1}{Q} \sum_{q=1}^{Q} \sum_{i=1}^{n}\left|x_{i, q+1}-x_{i, q}\right|
$$

in which $Q$ is the number of rebalances realised, $x_{i, q}$ is the portfolio weight of asset $i$ at time $q$ and $x_{i, q+1}$ is the portfolio weight after rebalancing. The value of this statistic equals the average monthly amount of buy and sells transactions as a percentage of the portfolio value. Thus, a greater value of $T O$ indicates a more expensive investment strategy. 


\section{Empirical Analysis}

The study starts with a comparison among the equally weighted strategy (EW), the minimum variance strategy $(\mathrm{minV})$ and risk parity strategy for only two macro investment categories (bond and equity) without regarding of the different specialisation of our sample of ETFs. Tables 2 and 3 display the in-sample and out-of-sample results.

Table 2

In-Sample Two-Group Strategies Results

\begin{tabular}{lllllllll}
\hline Strategy name & MaxRC & NHRC & NHX & MaxGRC & NGHRC & NGHX & AnStocks & STDnStocks \\
\hline EW & 0.0392 & 0.9864 & 1 & 0.9572 & 0.1635 & 0.9949 & 56 & 0 \\
minV & 0.9126 & 0.1669 & 0.1669 & 0.9986 & 0.0055 & 0.0056 & 6.1860 & 1.3512 \\
RP2G & 0.4145 & 0.8049 & 0.9342 & 0.5002 & 1 & 0.2759 & 21.8372 & 5.1078 \\
\hline
\end{tabular}

Table 3

Out-of-Sample Two-Group Strategies Results

\begin{tabular}{llll}
\hline Strategy name & TO & SR & MDD \\
\hline EW & 0 & 0.6482 & 0.1324 \\
minV & 0.0358 & -0.3213 & 0.0144 \\
RP2G & 0.3647 & 0.2699 & 0.0447 \\
\hline
\end{tabular}

The equally weighted strategy (EW) includes all the ETFs used in the study which were classified either as bond or equity. This strategy shows a very good performance (the Sharpe ratio is 0.6482), no change in the portfolio composition is required (turnover equals to 0 ) but the maximum drawdown is quite high (0.1324), and the risk concentration at group level is very high (0.9864), even if the maximum risk concentration on a specific ETF is very low (0.0392). In practice, as Figure 2 shows, most of the risk is caused by equity (0.9572), even if bond and equity groups are equally weighted. On the other side, the minimum variance portfolio ( $\operatorname{minV}$ ) presents a very strong concentration in a single assets group (bond ETFs, with a weight close to 100\%) and a limited diversification among ETFs (the total number of EFTs is around 6-7 and the maximum risk concentration is 0.9126$)$, a negative performance $(\mathrm{SR}=-0.3212)$ but a low maximum drawdown compared to EW.

The risk parity strategy we found is able to balance the risk contribution of the two assets categories (50\% bond ETFs, 50\% equity ETFs) with a restricted number of ETFs (between 22 and 27 with a strong concentration on bond EFTs) and a positive performance. The SR of this strategy (0.2699) is lower than the results obtained with the EW strategy and requests a certain turnover in the portfolio composition (that causes costs). However, it can reduce the maximum drawdown drastically, limiting volatility of portfolio results for the householder we consider as our target investor.

As the second step, we focus our attention at the eight investment categories EFTs we are studying and can be classified into. The idea is to detect the results of the EW strategy obtained using all the ETFs classes as a benchmark and to identify other strategies that work better. It means we are looking for strategies which permit to replicate the benchmark in term of risk contribution and return but with a lower number of EFTs, allowing to reduce the effort required when a broad portfolio is managed, especially from the perspective of a non-professional investor. 
Tables 4 and 5 show the results of the 16 strategies we used, combining different constraints in term of maximum weight for each ETFs category and each single ETF constituents the portfolio. From Table 4, Table 5, and Figure 3, we can observe that for each sub-set of strategies (same $U_{s}$, but different $u_{i}$ ), the number of ETFs in portfolio decreases any time we relax the constraint on the maximum weight for each ETF (higher $u_{i}$ ). It goes together with an increase in the maximum risk concentration on a specific ETF and a lowering in the maximum group risk concentration. Also, the turnover usually increases reducing the bounds on the weight of a specific ETF.

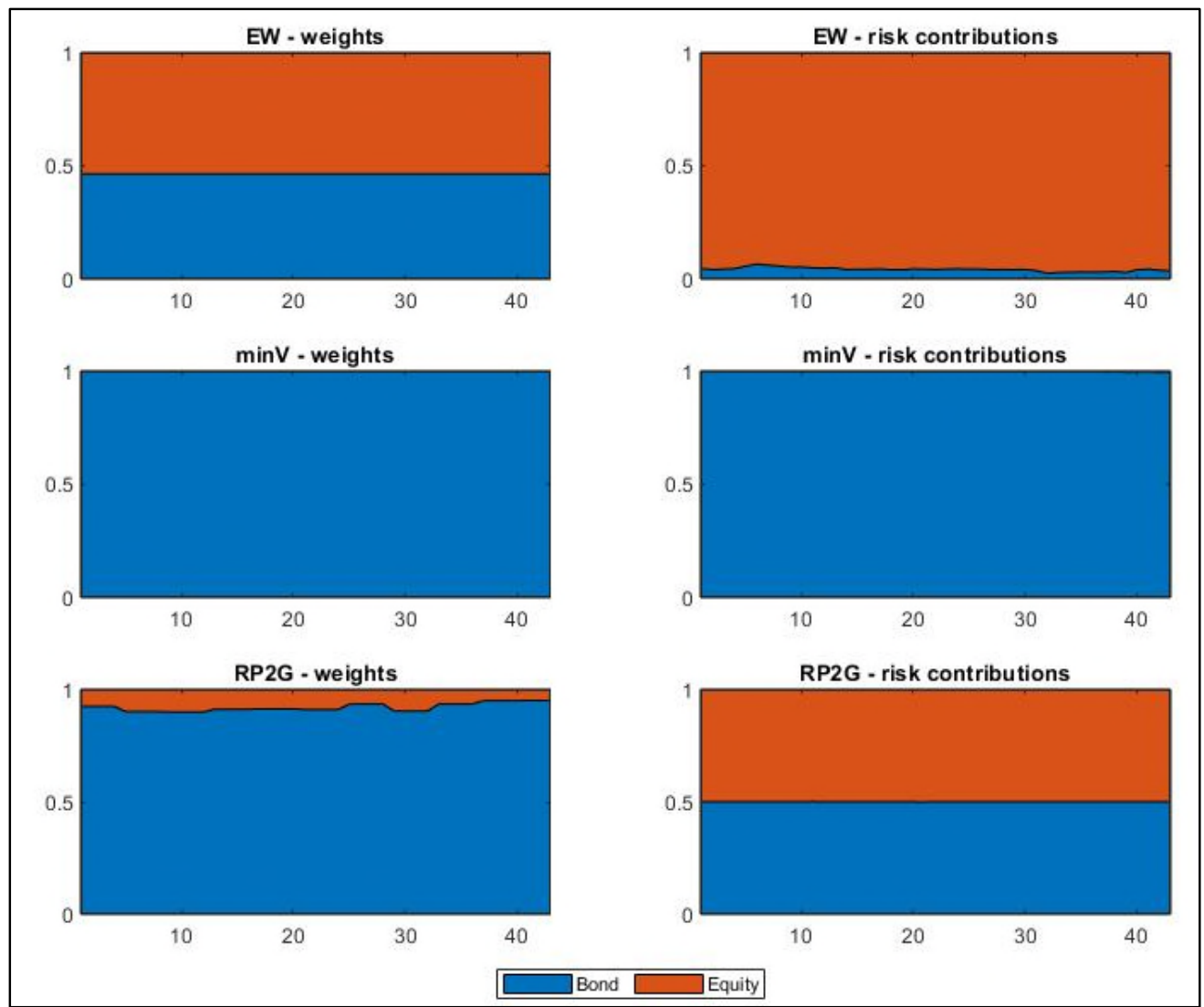

Figure 2. Evolution of Bond/Equity group weights (left) and risk contributions (right) for EW, minV, and RP2G portfolios.

Table 4

In-Sample Eight-Group Strategies Results

\begin{tabular}{|c|c|c|c|c|c|c|c|c|c|}
\hline Strategy name & Constraints & $\operatorname{maxRC}$ & NHRC & NHX & $\max G R C$ & NGHRC & NGHX & AnStocks & $\begin{array}{l}\text { STDnSto } \\
\text { cks }\end{array}$ \\
\hline $\mathrm{RP}_{8} \mathrm{G}_{1}$ & $\mathrm{U}_{\mathrm{s}}=15 \%, \mathrm{u}_{\mathrm{i}}=2 \%$ & 0.0395 & 0.9859 & 0.9974 & 0.2040 & 0.9603 & 0.9787 & 49.9535 & 1.7778 \\
\hline $\mathrm{RP} 8 \mathrm{G}_{2}$ & $\mathrm{U}_{\mathrm{s}}=15 \%, \mathrm{u}_{\mathrm{i}}=5 \%$ & 0.0801 & 0.9561 & 0.9703 & 0.1674 & 0.9660 & 0.9963 & 23.1395 & 0.9043 \\
\hline $\mathrm{RP} \mathrm{G}_{3}$ & $\mathrm{U}_{\mathrm{s}}=15 \%, \mathrm{u}_{\mathrm{i}}=10 \%$ & 0.1486 & 0.9114 & 0.9344 & 0.1654 & 0.9696 & 0.9959 & 15.5116 & 0.7273 \\
\hline $\mathrm{RP}_{4} \mathrm{G}_{4}$ & $\mathrm{U}_{\mathrm{s}}=15 \%, \mathrm{u}_{\mathrm{i}}=100 \%$ & 0.1650 & 0.8805 & 0.8945 & 0.1657 & 0.9717 & 0.9953 & 9.7674 & 1.3090 \\
\hline $\mathrm{RP} 8 \mathrm{G}_{5}$ & $\mathrm{U}_{\mathrm{s}}=20 \%, \mathrm{u}_{\mathrm{i}}=2 \%$ & 0.0395 & 0.9860 & 0.9978 & 0.2039 & 0.9606 & 0.9755 & 50.9535 & 2.1345 \\
\hline $\mathrm{RP} \mathrm{G}_{6}$ & $\mathrm{U}_{\mathrm{s}}=20 \%, \mathrm{u}_{\mathrm{i}}=5 \%$ & 0.0912 & 0.9513 & 0.9706 & 0.1623 & 0.9728 & 0.9816 & 24.1163 & 0.8130 \\
\hline $\mathrm{RP}_{8} \mathrm{G}_{7}$ & $\mathrm{U}_{\mathrm{s}}=20 \%, \mathrm{u}_{\mathrm{i}}=10 \%$ & 0.1478 & 0.9023 & 0.9273 & 0.1593 & 0.9786 & 0.9813 & 15.1395 & 0.9043 \\
\hline RP8G8 & $\mathrm{U}_{\mathrm{s}}=20 \%, \mathrm{u}_{\mathrm{i}}=100 \%$ & 0.1561 & 0.8888 & 0.8799 & 0.1573 & 0.9820 & 0.9811 & 9.7674 & 1.3266 \\
\hline $\mathrm{RP}_{8} \mathrm{G}_{9}$ & $\mathrm{U}_{\mathrm{s}}=30 \%, \mathrm{u}_{\mathrm{i}}=2 \%$ & 0.0410 & 0.9849 & 0.9980 & 0.1742 & 0.9667 & 0.9571 & 51.0930 & 0.2905 \\
\hline
\end{tabular}


(Table 4 to be continued)

\begin{tabular}{llllllllll}
\hline RP8G 10 & $\mathrm{U}_{\mathrm{s}}=30 \%, \mathrm{u}_{\mathrm{i}}=5 \%$ & 0.1209 & 0.9419 & 0.9711 & 0.1447 & 0.9907 & 0.9061 & 25.0698 & 0.9250 \\
RP8G $_{11}$ & $\mathrm{U}_{\mathrm{s}}=30 \%, \mathrm{u}_{\mathrm{i}}=10 \%$ & 0.1385 & 0.9102 & 0.9338 & 0.1390 & 0.9948 & 0.9061 & 14.4884 & 1.5756 \\
RP8G $_{12}$ & $\mathrm{U}_{\mathrm{s}}=30 \%, \mathrm{u}_{\mathrm{i}}=100 \%$ & 0.1342 & 0.9058 & 0.8521 & 0.1346 & 0.9969 & 0.9062 & 11.7907 & 2.8165 \\
RP8G $_{13}$ & $\mathrm{U}_{\mathrm{s}}=100 \%, \mathrm{u}_{\mathrm{i}}=2 \%$ & 0.0464 & 0.9822 & 0.9983 & 0.1631 & 0.9713 & 0.9109 & 53.3953 & 0.4889 \\
RP8G $_{14}$ & $\mathrm{U}_{\mathrm{s}}=100 \%, \mathrm{u}_{\mathrm{i}}=5 \%$ & 0.1080 & 0.9507 & 0.9740 & 0.1306 & 0.9998 & 0.7367 & 35.4186 & 11.9791 \\
RP8G $_{15}$ & $\mathrm{U}_{\mathrm{s}}=100 \%, \mathrm{u}_{\mathrm{i}}=10 \%$ & 0.1095 & 0.9674 & 0.9488 & 0.1255 & 1.0000 & 0.6922 & 44.3023 & 6.0137 \\
RP8G $_{16}$ & $\mathrm{U}_{\mathrm{s}}=100 \%, \mathrm{u}_{\mathrm{i}}=100 \%$ & 0.1159 & 0.9613 & 0.8963 & 0.1256 & 1.0000 & 0.6404 & 39.3721 & 4.0636 \\
\hline
\end{tabular}

Table 5

Out-of-Sample Eight-Group Strategies Results

\begin{tabular}{|c|c|c|c|c|}
\hline Strategy name & Constrainstains & TO & SR & MDD \\
\hline $\mathrm{RP} 8 \mathrm{G}_{1}$ & $\mathrm{U}_{\mathrm{s}}=15 \%, \mathrm{u}_{\mathrm{i}}=2 \%$ & 0.0285 & 0.6183 & 0.1534 \\
\hline $\mathrm{RP} 8 \mathrm{G}_{2}$ & $\mathrm{U}_{\mathrm{s}}=15 \%, \mathrm{u}_{\mathrm{i}}=5 \%$ & 0.0878 & 0.6305 & 0.1663 \\
\hline $\mathrm{RP} 8 \mathrm{G}_{3}$ & $\mathrm{U}_{\mathrm{s}}=15 \%, \mathrm{u}_{\mathrm{i}}=10 \%$ & 0.0950 & 0.5936 & 0.1620 \\
\hline $\mathrm{RP} 8 \mathrm{G}_{4}$ & $\mathrm{U}_{\mathrm{s}}=15 \%, \mathrm{u}_{\mathrm{i}}=100 \%$ & 0.0890 & 0.5724 & 0.1585 \\
\hline $\mathrm{RP} \mathrm{G}_{5}$ & $\mathrm{U}_{\mathrm{s}}=20 \%, \mathrm{u}_{\mathrm{i}}=2 \%$ & 0.0313 & 0.6405 & 0.1498 \\
\hline $\mathrm{RP} \mathrm{G}_{6}$ & $\mathrm{U}_{\mathrm{s}}=20 \%, \mathrm{u}_{\mathrm{i}}=5 \%$ & 0.1027 & 0.6378 & 0.1440 \\
\hline $\mathrm{RP} 8 \mathrm{G}_{7}$ & $\mathrm{U}_{\mathrm{s}}=20 \%, \mathrm{u}_{\mathrm{i}}=10 \%$ & 0.0931 & 0.5984 & 0.1401 \\
\hline $\mathrm{RP}_{8} \mathrm{G}_{8}$ & $\mathrm{U}_{\mathrm{s}}=20 \%, \mathrm{u}_{\mathrm{i}}=100 \%$ & 0.0770 & 0.5875 & 0.1388 \\
\hline $\mathrm{RP} 8 \mathrm{G}_{9}$ & $\mathrm{U}_{\mathrm{s}}=30 \%, \mathrm{u}_{\mathrm{i}}=2 \%$ & 0.0167 & 0.6531 & 0.1364 \\
\hline $\mathrm{RP} \mathrm{G}_{10}$ & $\mathrm{U}_{\mathrm{s}}=30 \%, \mathrm{u}_{\mathrm{i}}=5 \%$ & 0.0881 & 0.6461 & 0.0985 \\
\hline $\mathrm{RP} \mathrm{G}_{11}$ & $\mathrm{U}_{\mathrm{s}}=30 \%, \mathrm{u}_{\mathrm{i}}=10 \%$ & 0.1370 & 0.6092 & 0.0957 \\
\hline $\mathrm{RP} \mathrm{G}_{12}$ & $\mathrm{U}_{\mathrm{s}}=30 \%, \mathrm{u}_{\mathrm{i}}=100 \%$ & 0.1494 & 0.5807 & 0.0948 \\
\hline $\mathrm{RP}_{13}$ & $\mathrm{U}_{\mathrm{s}}=100 \%, \mathrm{u}_{\mathrm{i}}=2 \%$ & 0.0294 & 0.6602 & 0.1170 \\
\hline $\mathrm{RP}_{14}$ & $\mathrm{U}_{\mathrm{s}}=100 \%, \mathrm{u}_{\mathrm{i}}=5 \%$ & 0.0832 & 0.7111 & 0.0447 \\
\hline $\mathrm{RP}_{15}$ & $\mathrm{U}_{\mathrm{s}}=100 \%, \mathrm{u}_{\mathrm{i}}=10 \%$ & 0.1723 & 0.7385 & 0.0373 \\
\hline $\mathrm{RP} \mathrm{G}_{16}$ & $\mathrm{U}_{\mathrm{s}}=100 \%, \mathrm{u}_{\mathrm{i}}=100 \%$ & 0.1847 & 0.6655 & 0.0342 \\
\hline
\end{tabular}

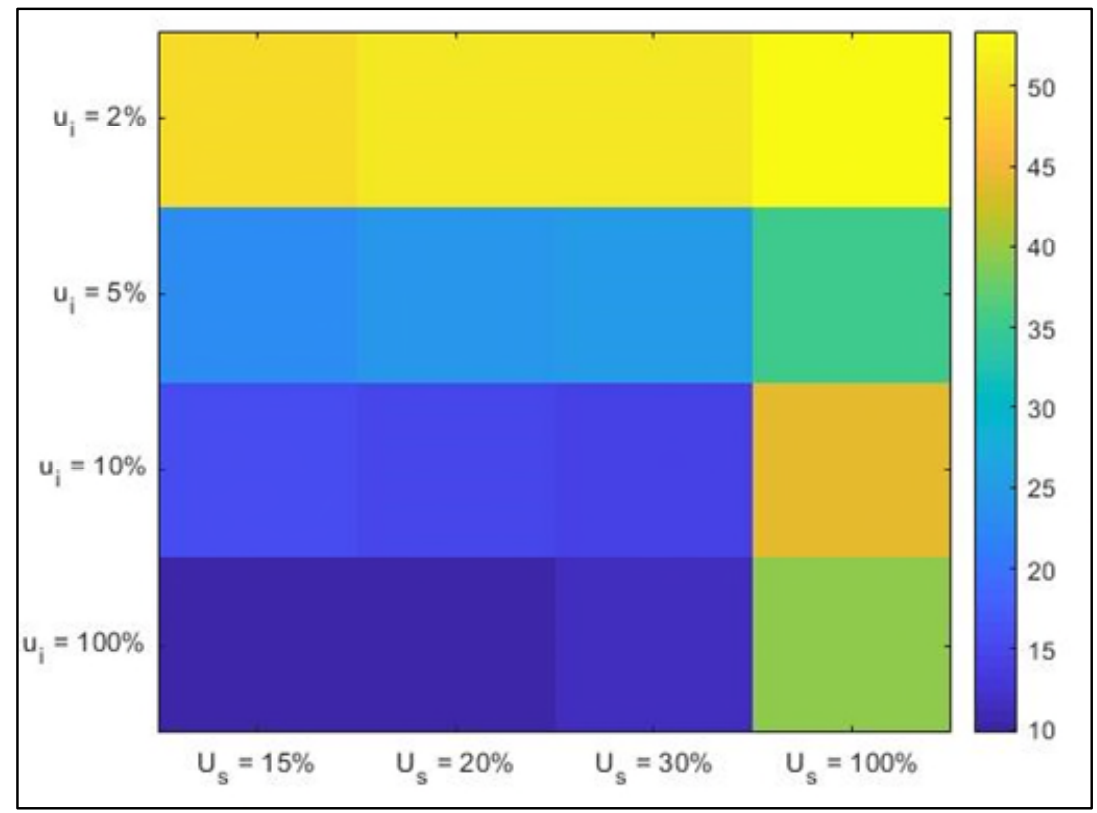

Figure 3. Colour matrix is representing the average number of ETFs with a positive weight for each variant of the eight groups risk parity strategy. 
Analysing the different strategies more in detail, we can observe that the strategy $\mathrm{RP} \mathrm{G}_{16}$ represents the group risk parity without any bound: The maximum risk contribution of every single ETF is 0.1159 , and the risk contribution of each ETF category is closed to the previous value (0.1256). The Sharpe ratio for this strategy is high (0.6655), and the result is obtained with a subset of the total ETFs under scrutiny (AnStocks = 39.3721, STDnStocks = 4.0636), which permits to reduce the MDD. In terms of constituents of this portfolio, Eurozone Government Bond ETFs and Euro Corporate Bond ETFs present the higher weights, with other categories that are only limited represented in the portfolio (see Figure 4).

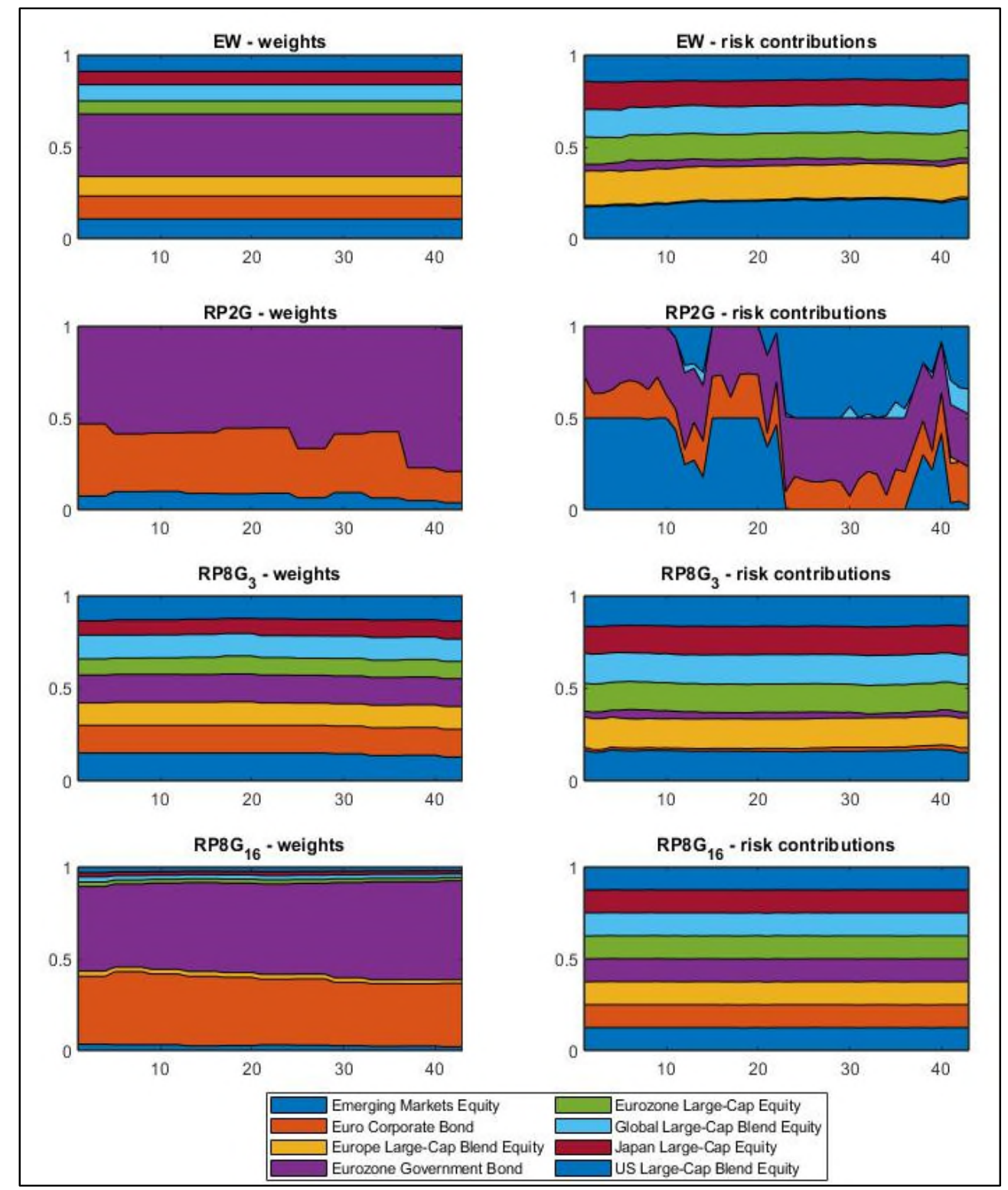

Figure 4. Evolution of group weights (left) and group risk contributions (right) for EW, RP2G, RP8G, and RP8G 16 portfolios when the pool of ETFs is divided into eight classes.

We can observe from Figure 4 that strategy $\mathrm{RP} 8 \mathrm{G}_{2}$ presents some relevant particularities: Even if the portfolio is composed mainly by Eurozone Government Bond ETFs and by Euro Corporate Bond ETFs, the 
most relevant equity category is Emerging Markets Equity EFTs. Even if equity ETFs weight poorly on the portfolio, around 50\% of its risk contribution is caused by Emerging Markets Equity EFTs.

The same Figure 4 permits to consider a singular strategy $\left(\mathrm{RP}_{3} \mathrm{G}_{3}\right)$ that presents an upper limit at $15 \%$ for each ETF category and an upper limit at $10 \%$ for each specific ETF. With this strategy, any ETF category is represented (and there is no dominance of bonds investment) with a not so different weight among categories, such as the risk contribution is well-distributed among categories. For this strategy, the maximum risk concentration is at the upper level compared to other strategies ( $\operatorname{maxRC}=0.1486)$, such as the maximum group risk contribution (maxGRC $=0.1654$ ). However, the number of EFTs required by the strategy is limited (AnStocks $=15.5116)$ with a limited standard deviation, the turnover is limited $(\mathrm{TO}=0.0950)$, and the Sharpe ratio is very good $(\mathrm{SR}=0.5936)$. It happens at expenses of a quite relevant maximum drawdown $(\mathrm{MDD}=$ $0.1620)$.

Figure 5 draws all the performances of the 19 different strategies we described in Tables from 2 to 5 . Overall, the equally weighted (EW) presents high volatility but shows a very good performance, even if it is not the best one; many other strategies are similar in term of performance even if are less effective in terms of risk contribution.

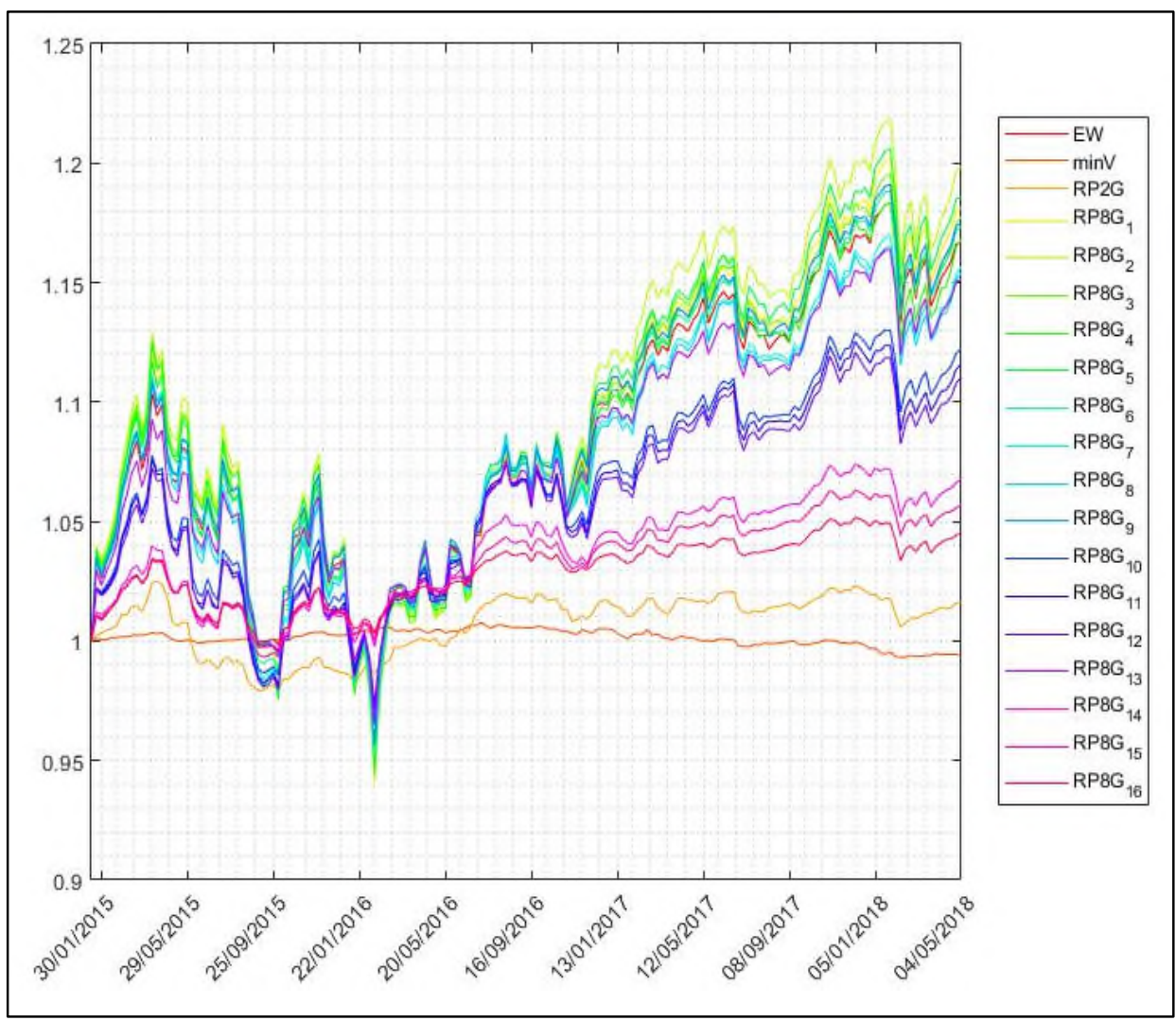

Figure 5. Cumulative out-of-sample portfolio returns for all the portfolio models compared in the empirical study.

Figure 6 compares the performance of some of the most relevant strategies. The minimum variance strategy $(\mathrm{minV})$ presents a poor performance, but—in some periods-even better than the RP2G, the strategy that combines bond and equity instruments with a balanced risk contribution. EW is-as already told-the benchmark in term of performance. Strategy $\mathrm{RP} 8 \mathrm{G}_{3}$ permits to reach a very similar result with a lower number 
of ETFs (around 15 against 56) and a better diversification thanks to the lower maximum group risk contribution (0.1654 vs. 0.9572$)$. The turnover is only slightly higher for the RP8G3 strategy compared to EW strategy (0.095 vs. 0$)$, but the maximum drawdown is higher $(\mathrm{MDD}=0.1324$ for $\mathrm{EW}$ and $\mathrm{MDD}=0.1620$ for $\mathrm{RP}_{3} \mathrm{G}_{3}$.

Handling the bounds on the groups and on the individual assets, we obtained a strategy that presents very good characteristics permitting an investor to diversify better than with the EW strategy, with lower effort in managing the portfolio (thanks to the lower number of products required to build it) and a performance in line with EW strategy.

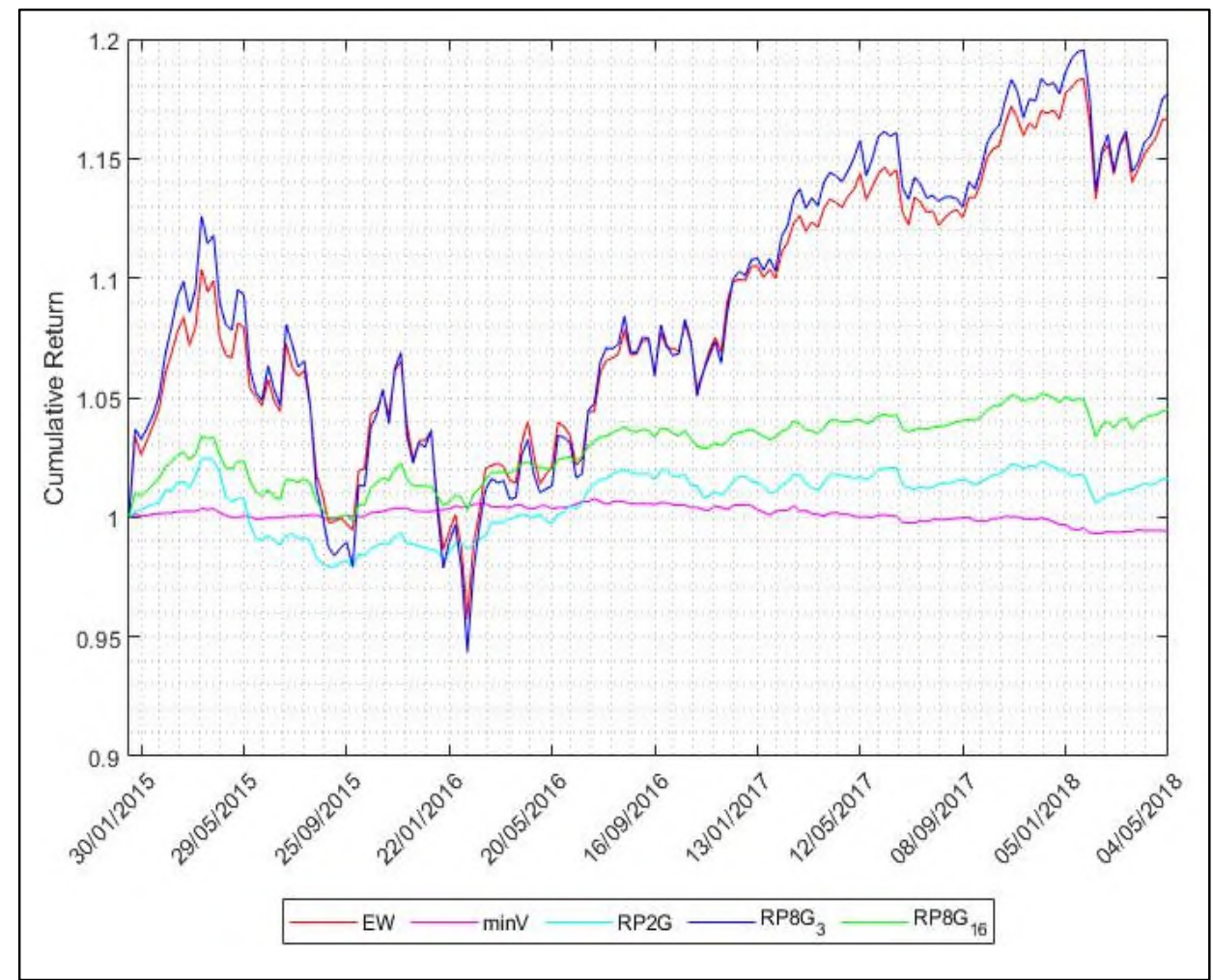

Figure 6. Cumulative out-of-sample portfolio returns for the $\mathrm{EW}, \mathrm{minV}, \mathrm{RP} 2 \mathrm{G}$, and two selected risk parity strategies for eight groups of ETFs.

\section{Conclusions and Future Works}

In this article, we deal with the problem of managing a portfolio of investment in the perspective of a householder investor who wants to control the risk using ETFs and the group risk parity strategy. Further, we investigate the role of granularity and bounds on the groups and the individual weights in portfolio diversification and risk contribution. The numerical experiments over a basket of selected ETFs have put in evidence that it is possible to identify optimal portfolios that benefit of both capital and risk diversifications with a limited number of individual ETFs able to represent all the different categories of ETFs we employed. Next step will be to investigate the effectiveness of group risk parity for institutional investors that usually have to select portfolios composed by a reduced number of constituents from a large basket of financial instruments, even involving thousands of items. 


\section{References}

Abner, D. J. (2016). The ETF handbook: How to value and trade exchange traded funds. Verlag: John Wiley \& Sons.

Bai, X., Scheinberg, K., \& Tutuncu, R. (2016). Least-squares approach to risk parity in portfolio selection. Quantitative Finance, 16(3), 357-376.

Best, M. J., \& Grauer, R. R. (1991). On the sensitivity of mean-variance-efficient portfolios to changes in asset means: Some analytical and computational results. The Review of Financial Studies, 4(2), 315-342.

Bogle, J. C. (2015). Bogle on mutual funds: New perspectives for the intelligent investor. Verlag: John Wiley \& Sons.

Braga, M. D. (2015). Risk parity versus other $\mu$-free strategies: A comparison in a triple view. Investment Management and Financial Innovations, 12(2), 277-289.

Buetow, G. W., \& Henderson, B. J. (2012). An empirical analysis of exchange-traded funds. Journal of Portfolio Management, $38(4), 112-127$.

Calvet, L. E., Campbell, J. Y., \& Sodini, P. (2007). Down or out: Assessing the welfare costs of household investment mistakes. Journal of Political Economy, 115(5), 707-747.

Cass, D., \& Stiglitz, J. E. (1970). The structure of investor preferences and asset returns, and separability in portfolio allocation: A contribution to the pure theory of mutual funds. Journal of Economic Theory, 2(2), 122-160.

Cesarone, F., \& Colucci, S. (2018). Minimum risk versus capital and risk diversification strategies for portfolio construction. Journal of the Operational Research Society, 69(2), 183-200.

Clarke, R., De Silva, H., \& Thorley, S. (2011). Minimum-variance portfolio composition. Journal of Portfolio Management, $37(2), 31$.

DeMiguel, V., Garlappi, L., \& Uppal, R. (2007). Optimal versus naive diversification: How inefficient is the $1 / \mathrm{N}$ portfolio strategy? The Review of Financial Studies, 22(5), 1915-1953.

Eakins, S. G., \& Stansell, S. (2007). An examination of alternative portfolio rebalancing strategies applied to sector funds. Journal of Asset Management, 8(1), 1-8.

EY. (2017). Global ETF Research 2017-Reshaping around the investor. Retrieved from http://www.ey.com/gl/en/industries/financial-services/asset-management/ey-global-etf-survey-2017

Gluzicka, A. (2017). Risk parity portfolios for the grouped stocks. In K. Jajuga, L. T. Orlowski, and K. Staehr (Eds.), Contemporary trends and challenges in finance (pp. 81-89). Cham: Springer.

Goetzmann, W. N., \& Kumar, A. (2008). Equity portfolio diversification. Review of Finance, 12(3), 433-463.

Hill, J. M., Nadig, D., \& Hougan, M. (2015). A comprehensive guide to exchange-traded funds (ETFs). CFA Institute Research Foundation. Retrieved from http://www.cetfa.ca/files/1433184781_CFA\%20-\%20ETF\%20Report.pdf

Hitaj, A., \& Zambruno, G. (2016). Are Smart Beta strategies suitable for hedge fund portfolios? Review of Financial Economics, 29, 37-51.

Huang, M. Y., \& Lin, J. B. (2011). Do ETFs provide effective international diversification? Research in International Business and Finance, 25(3), 335-344.

Itzhak, B. D., Franzoni, F. A., \& Moussawi, R. (2017). Exchange traded funds (ETFs). Working paper. Retrieved from http://www.ssrn.com/abstract=2865734

Ivković, Z., Sialm, C., \& Weisbenner, S. (2008). Portfolio concentration and the performance of individual investors. Journal of Financial and Quantitative Analysis, 43(3), 613-655.

Kelly, M. (1995). All their eggs in one basket: Portfolio diversification of US households. Journal of Economic Behavior \& Organization, 27(1), 87-96.

Khuzwayo, B. (2011). Diversification in portfolio construction: Can it lead to outperformance. Research Report, Cape Town, Cadiz Quantitative Research.

Kumar, A. (2009). Who gambles in the stock market? The Journal of Finance, 64(4), 1889-1933.

Ledoit, O., \& Wolf, M. (2003). Improved estimation of the covariance matrix of stock returns with an application to portfolio selection. Journal of Empirical Finance, 10(5), 603-621.

Ledoit, O., \& Wolf, M. (2004). Honey, I shrunk the sample covariance matrix. Journal of Portfolio Management, 30(4), 110-119. Lee, W. (2011). Risk-based asset allocation: A new answer to an old question? Journal of Portfolio Management, 37(4), 11-28.

Lettau, M., \& Madhavan, A. (2018). Exchange-traded funds 101 for economists. Journal of Economic Perspectives, 32(1), 135-154.

Lohre, H., Neugebauer, U., \& Zimmer, C. (2012). Diversified risk parity strategies for equity portfolio selection. Journal of Investing, 21(3), 111-128. 
Maillard, S., Roncalli, T., \& Teïletche, J. (2010). The properties of equally weighted risk contribution portfolios. Journal of Portfolio Management, 36(4), 60.

Malkiel, B. G. (1995). Returns from investing in equity mutual funds 1971 to 1991. The Journal of Finance, 50(2), 549-572.

Markowitz, H. (1952) Portfolio selection. The Journal of Finance, 7(1), 77-91.

Merton, R. (1971) Optimum consumption and portfolio rules in a continuous-time model. Journal of Economic Theory, 3, 373-413.

Morningstar. (2018). Investing glossary-Morningstar rating for funds. Retrieved from http://www.morningstar.com/InvGlossary/morningstar_rating_for_funds.aspx

Munro, B., \& Bradfield, D. (2016). Putting the squeeze on the sample covariance matrix for portfolio construction. Investment Analysts Journal, 45(1), 47-62.

Polkovnichenko, V. (2005). Household portfolio diversification: A case for rank-dependent preferences. The Review of Financial Studies, 18(4), 1467-1502.

Puelz, D., Carvalho, C. M., \& Hahn, P. R. (2015). Optimal ETF selection for passive investing. Retrieved from https://arxiv.org/abs/1510.03385

Qian, E. (2005). Risk parity portfolios: Efficient portfolios through true diversification. Panagora Asset Management. Retrieved from https://www.panagora.com/assets/PanAgora-Risk-Parity-Portfolios-Efficient-Portfolios-Through-True-Diversification.pdf

Roche, H., Tompaidis, S., \& Yang, C. (2013). Why does junior put all his eggs in one basket? A potential rational explanation for holding concentrated portfolios. Journal of Financial Economics, 109(3), 775-796.

Roll, R. (2013). Volatility, correlation, and diversification in a multi-factor world. Journal of Portfolio Management, 39(2), 11-18. Roncalli, T. (2013). Introduction to risk parity and budgeting. Boca Raton, FL: CRC Press.

Sharpe, W. F. (1965). Risk-aversion in the stock market: Some empirical evidence. Santa Monica, California: Rand Corporation.

Siu, F. (2014). Risk parity strategies for equity portfolio management. Journal of Indexes, May/June, 18-25.

Tsai, P. J., \& Swanson, P. E. (2009). The comparative role of iShares and country funds in internationally diversified portfolios. Journal of Economics and Business, 61(6), 472-494. 


\section{Appendix}

Table 1A

List of ETfs Used in the Analysis

\begin{tabular}{|c|c|c|c|}
\hline Fund name & ISIN code & $\begin{array}{l}\text { Bloomberg } \\
\text { ticker }\end{array}$ & Category \\
\hline $\begin{array}{l}\text { Amundi ETF Govt Bond EuroMTS Broad Investment Grade 10-15 } \\
\text { UCITS ETF EUR }\end{array}$ & FR0010754143 & $\mathrm{C} 10$ & $\begin{array}{l}\text { Eurozone Government } \\
\text { Bond }\end{array}$ \\
\hline $\begin{array}{l}\text { Amundi ETF Govt Bond EuroMTS Broad Investment Grade 3-5 UCITS } \\
\text { ETF EUR }\end{array}$ & FR0010754168 & C33 & $\begin{array}{l}\text { Eurozone Government } \\
\text { Bond }\end{array}$ \\
\hline $\begin{array}{l}\text { Amundi ETF Govt Bond EuroMTS Broad Investment Grade 5-7 UCITS } \\
\text { ETF EUR }\end{array}$ & FR0010754176 & C53 & $\begin{array}{l}\text { Eurozone Government } \\
\text { Bond }\end{array}$ \\
\hline $\begin{array}{l}\text { Amundi ETF Govt Bond EuroMTS Broad Investment Grade 7-10 UCITS } \\
\text { ETF EUR }\end{array}$ & FR0010754184 & $\mathrm{C} 73$ & $\begin{array}{l}\text { Eurozone Government } \\
\text { Bond }\end{array}$ \\
\hline Amundi EURO Corporate Ex Financials IBOXX UCITS ETF-C EUR & LU1681040140 & AXFI & Euro Corporate Bond \\
\hline Amundi EURO Corporate Financials IBOXX UCITS ETF-C EUR & LU1681040066 & AFIN & Euro Corporate Bond \\
\hline Amundi EURO STOXX 50 UCITS ETF-C EUR EUR & LU1681047236 & $\mathrm{C} 50$ & $\begin{array}{l}\text { Eurozone Large-Cap } \\
\text { Equity }\end{array}$ \\
\hline $\begin{array}{l}\text { Amundi Govt Bond Highest Rated Euromts Investment Grade UCITS } \\
\text { ETF-C EUR }\end{array}$ & LU1681046691 & AM3A & $\begin{array}{l}\text { Eurozone Government } \\
\text { Bond }\end{array}$ \\
\hline iShares $€$ Govt Bond 3-7yr UCITS ETF EUR (Acc) EUR & IE00B3VTML14 & CSBGE7 & $\begin{array}{l}\text { Eurozone Government } \\
\text { Bond }\end{array}$ \\
\hline iShares Core EURO STOXX 50 UCITS ETF EUR (Acc) EUR & IE00B53L3W79 & CSSX5E & $\begin{array}{l}\text { Eurozone Large-Cap } \\
\text { Equity }\end{array}$ \\
\hline iShares Core MSCI Japan IMI UCITS ETF USD (Acc) EUR & IE00B4L5YX21 & SJPA & Japan Large-Cap Equity \\
\hline iShares Core MSCI World UCITS ETF USD (Acc) EUR & IE00B4L5Y983 & SWDA & $\begin{array}{l}\text { Global Large-Cap Blend } \\
\text { Equity }\end{array}$ \\
\hline iShares Core S\&P 500 UCITS ETF USD (Acc) EUR & IE00B5BMR087 & CSSPX & $\begin{array}{l}\text { US Large-Cap Blend } \\
\text { Equity }\end{array}$ \\
\hline iShares MSCI EM UCITS ETF USD (Acc) EUR & IE00B4L5YC18 & SEMA & $\begin{array}{l}\text { Emerging Markets } \\
\text { Equity }\end{array}$ \\
\hline iShares MSCI EMU UCITS ETF EUR (Acc) EUR & IE00B53QG562 & CSEMU & $\begin{array}{l}\text { Eurozone Large-Cap } \\
\text { Equity }\end{array}$ \\
\hline iShares MSCI Europe UCITS ETF EUR (Acc) EUR & IE00B4K48X80 & SMEA & $\begin{array}{l}\text { Europe Large-Cap } \\
\text { Blend Equity }\end{array}$ \\
\hline iShares MSCI Japan UCITS ETF USD (Acc) EUR & IE00B53QDK08 & CSJP & Japan Large-Cap Equity \\
\hline iShares MSCI USA UCITS ETF USD (Acc) EUR & IE00B52SFT06 & CSUS & $\begin{array}{l}\text { US Large-Cap Blend } \\
\text { Equity }\end{array}$ \\
\hline iShares Nikkei 225 UCITS ETF JPY (Acc) EUR & IE00B52MJD48 & CSNKY & Japan Large-Cap Equity \\
\hline Lyxor Euro Corporate Bond ex Financials UCITS ETF Acc EUR & FR0010814236 & $\mathrm{CBEF}$ & Euro Corporate Bond \\
\hline Lyxor Euro Corporate Bond UCITS ETF Acc EUR & FR0010737544 & CRPE & Euro Corporate Bond \\
\hline $\begin{array}{l}\text { Lyxor EUROMTS 5-7Y Investment Grade (DR) UCITS ETF-C-EUR } \\
\text { EUR }\end{array}$ & LU1287023003 & EM57 & $\begin{array}{l}\text { Eurozone Government } \\
\text { Bond }\end{array}$ \\
\hline $\begin{array}{l}\text { Lyxor EUROMTS 7-10Y Investment Grade (DR) UCITS ETF-C-EUR } \\
\text { EUR }\end{array}$ & LU1287023185 & EM710 & $\begin{array}{l}\text { Eurozone Government } \\
\text { Bond }\end{array}$ \\
\hline $\begin{array}{l}\text { Lyxor EuroMTS Highest Rated Macro-Weighted Govt Bond 1-3Y (DR) } \\
\text { UCITS ETF Acc EUR }\end{array}$ & FR0011146315 & AAA13 & $\begin{array}{l}\text { Eurozone Government } \\
\text { Bond }\end{array}$ \\
\hline $\begin{array}{l}\text { Lyxor EuroMTS Highest Rated Macro-Weighted Govt Bond 3-5Y (DR) } \\
\text { UCITS ETF Acc EUR }\end{array}$ & FR0011146349 & AAA35 & $\begin{array}{l}\text { Eurozone Government } \\
\text { Bond }\end{array}$ \\
\hline $\begin{array}{l}\text { Lyxor EuroMTS Highest Rated Macro-Weighted Govt Bond 5-7Y (DR) } \\
\text { UCITS ETF Acc EUR }\end{array}$ & FR0011146356 & AAA57 & $\begin{array}{l}\text { Eurozone Government } \\
\text { Bond }\end{array}$ \\
\hline Lyxor MSCI All Country World UCITS ETF C-EUR EUR & FR0011079466 & ACWI & $\begin{array}{l}\text { Global Large-Cap Blend } \\
\text { Equity }\end{array}$ \\
\hline
\end{tabular}


(Table 1A to be continued)

\begin{tabular}{|c|c|c|c|}
\hline Lyxor MSCI Emerging Markets UCITS ETF C-EUR EUR & FR0010429068 & EMKT & $\begin{array}{l}\text { Emerging Markets } \\
\text { Equity }\end{array}$ \\
\hline Lyxor EuroMTS 3-5Y INVESTMENT GRADE (DR) UCITS ETF-Acc & LU1650488494 & EM35 & $\begin{array}{l}\text { Eurozone Government } \\
\text { Bond }\end{array}$ \\
\hline Lyxor EuroMTS All-Maturity Investment Grade (DR) UCITS ETF-Acc & LU1650490474 & EMG & $\begin{array}{l}\text { Eurozone Government } \\
\text { Bond }\end{array}$ \\
\hline $\begin{array}{l}\text { Lyxor EuroMTS Highest Rated Macro-Weighted Govt Bond (DR) } \\
\text { UCITS ETF-Acc EUR }\end{array}$ & LU1287023342 & EMAAA & $\begin{array}{l}\text { Eurozone Government } \\
\text { Bond }\end{array}$ \\
\hline $\begin{array}{l}\text { Ossiam Emerging Markets Minimum Variance NR UCITS ETF 1C } \\
\text { (EUR) EUR }\end{array}$ & LU0705291903 & EMMV & $\begin{array}{l}\text { Emerging Markets } \\
\text { Equity }\end{array}$ \\
\hline $\begin{array}{l}\text { Ossiam iSTOXX }{ }^{\mathrm{TM}} \text { Europe Minimum Variance NR UCITS ETF 1C } \\
\text { (EUR) EUR }\end{array}$ & LU0599612842 & EUMV & $\begin{array}{l}\text { Europe Large-Cap } \\
\text { Blend Equity }\end{array}$ \\
\hline $\begin{array}{l}\text { Ossiam STOXX® Europe } 600 \text { Equal Weight NR UCITS ETF 1C (EUR) } \\
\text { EUR }\end{array}$ & LU0599613147 & S6EW & $\begin{array}{l}\text { Europe Large-Cap } \\
\text { Blend Equity }\end{array}$ \\
\hline Ossiam US Minimum Variance ESG NR UCITS ETF 1C (EUR) EUR & LU0599612685 & SPMV & $\begin{array}{l}\text { US Large-Cap Blend } \\
\text { Equity }\end{array}$ \\
\hline Ossiam World Minimum Variance NR UCITS ETF 1C (EUR) EUR & LU0799656698 & WOMV & $\begin{array}{l}\text { Global Large-Cap Blend } \\
\text { Equity }\end{array}$ \\
\hline SPDR® MSCI ACWI IMI UCITS ETF EUR & IE00B3YLTY66 & IMIE & $\begin{array}{l}\text { Global Large-Cap Blend } \\
\text { Equity }\end{array}$ \\
\hline SPDR® MSCI Emerging Markets UCITS ETF EUR & IE00B469F816 & EMRG & $\begin{array}{l}\text { Emerging Markets } \\
\text { Equity }\end{array}$ \\
\hline SPDR® MSCI Europe UCITS ETF EUR & IE00BKWQ0Q14 & EROX & $\begin{array}{l}\text { Europe Large-Cap } \\
\text { Blend Equity }\end{array}$ \\
\hline $\begin{array}{l}\text { UBS ETFs plc-MSCI Emerging Markets SF UCITS ETF (USD) A-acc } \\
\text { EUR }\end{array}$ & IE00B3Z3FS74 & EMGEAS & $\begin{array}{l}\text { Emerging Markets } \\
\text { Equity }\end{array}$ \\
\hline Xtrackers Euro Stoxx 50 UCITS ETF 1C EUR & LU0380865021 & XESC & $\begin{array}{l}\text { Eurozone Large-Cap } \\
\text { Equity }\end{array}$ \\
\hline Xtrackers II EUR Corporate Bond ex Financials UCITS ETF 1C EUR & LU0484968655 & XB4N & Euro Corporate Bond \\
\hline Xtrackers II EUR Corporate Bond UCITS ETF 1C EUR & LU0478205379 & XBLC & Euro Corporate Bond \\
\hline Xtrackers II EUR Covered Bond Swap UCITS ETF 1C EUR & LU0820950128 & XLIQ & Euro Corporate Bond \\
\hline Xtrackers II Eurozone Government Bond 3-5 UCITS ETF 1C EUR & LU0290356954 & $\mathrm{X} 35 \mathrm{E}$ & $\begin{array}{l}\text { Eurozone Government } \\
\text { Bond }\end{array}$ \\
\hline Xtrackers II Eurozone Government Bond 5-7 UCITS ETF 1C EUR & LU0290357176 & $\mathrm{X} 57 \mathrm{E}$ & $\begin{array}{l}\text { Eurozone Government } \\
\text { Bond }\end{array}$ \\
\hline Xtrackers II Eurozone Government Bond 7-10 UCITS ETF 1C EUR & LU0290357259 & $\mathrm{X} 710$ & $\begin{array}{l}\text { Eurozone Government } \\
\text { Bond }\end{array}$ \\
\hline Xtrackers II Eurozone Government Bond UCITS ETF 1C EUR & LU0290355717 & XGLE & $\begin{array}{l}\text { Eurozone Government } \\
\text { Bond }\end{array}$ \\
\hline $\begin{array}{l}\text { Xtrackers II iBoxx Eurozone Government Bond Yield Plus Swap UCITS } \\
\text { ETF 1C EUR }\end{array}$ & LU0524480265 & $\mathrm{XY} 4 \mathrm{P}$ & $\begin{array}{l}\text { Eurozone Government } \\
\text { Bond }\end{array}$ \\
\hline Xtrackers MSCI Emerging Markets Swap UCITS ETF 1C EUR & LU0292107645 & XMEM & Emerging Markets Equity \\
\hline Xtrackers MSCI Europe UCITS ETF 1C EUR & LU0274209237 & XMEU & $\begin{array}{l}\text { Europe Large-Cap } \\
\text { Blend Equity }\end{array}$ \\
\hline Xtrackers MSCI Japan UCITS ETF 1C EUR & LU0274209740 & XMJP & Japan Large-Cap Equity \\
\hline Xtrackers MSCI USA Swap UCITS ETF 1C EUR & LU0274210672 & XMUS & $\begin{array}{l}\text { US Large-Cap Blend } \\
\text { Equity }\end{array}$ \\
\hline Xtrackers MSCI World Swap UCITS ETF 1C EUR & LU0274208692 & XMWO & $\begin{array}{l}\text { Global Large-Cap Blend } \\
\text { Equity }\end{array}$ \\
\hline Xtrackers S \& P 500 Swap UCITS ETF 1C EUR & LU0490618542 & XSPX & $\begin{array}{l}\text { US Large-Cap Blend } \\
\text { Equity }\end{array}$ \\
\hline Xtrackers Stoxx Europe 600 UCITS ETF 1C EUR & LU0328475792 & XSX6 & $\begin{array}{l}\text { Europe Large-Cap } \\
\text { Blend Equity }\end{array}$ \\
\hline
\end{tabular}

